Rabaska

Revue d'ethnologie de l'Amérique française

\title{
Paul Jacob (1944-2011)
}

\section{Jocelyne Milot}

Volume 9, 2011

URI : https://id.erudit.org/iderudit/1005911ar

DOI : https://doi.org/10.7202/1005911ar

Aller au sommaire du numéro

Éditeur(s)

Société québécoise d'ethnologie

ISSN

1703-7433 (imprimé)

1916-7350 (numérique)

Découvrir la revue

Citer ce document

Milot, J. (2011). Paul Jacob (1944-2011). Rabaska, 9, 243-244.

https://doi.org/10.7202/1005911ar

Ce document est protégé par la loi sur le droit d'auteur. L'utilisation des services d'Érudit (y compris la reproduction) est assujettie à sa politique d'utilisation que vous pouvez consulter en ligne.

https://apropos.erudit.org/fr/usagers/politique-dutilisation/
Cet article est diffusé et préservé par Érudit.

Érudit est un consortium interuniversitaire sans but lucratif composé de l’Université de Montréal, l'Université Laval et l'Université du Québec à Montréal. Il a pour mission la promotion et la valorisation de la recherche. https://www.erudit.org/fr/ 


\section{Paul Jacob (1944-2011)}

Qui a rencontré Paul Jacob un jour ne risque pas de l'oublier. Originaire de Vallée-Jonction dans la Beauce, il se plaisait à dire que la paroisse de l'EnfantJésus de Vallée-Jonction était située entre SainteMarie et Saint-Joseph, tout juste en bas des SaintsAnges. C'est là que son cycle de vie a pris son envol en 1944 et a terminé sa course au printemps 2011.

Des études classiques à l'Externat Saint-JeanEudes, à Québec, développent son goût pour le latin, le grec et le français et l'initient au monde du théâtre, de la musique et de l'art oratoire. Ce goût de la parole et des mots ne se démentira jamais que ce soit par l'enseignement qui comblera sa vie, l'écriture ou la prise de parole lors

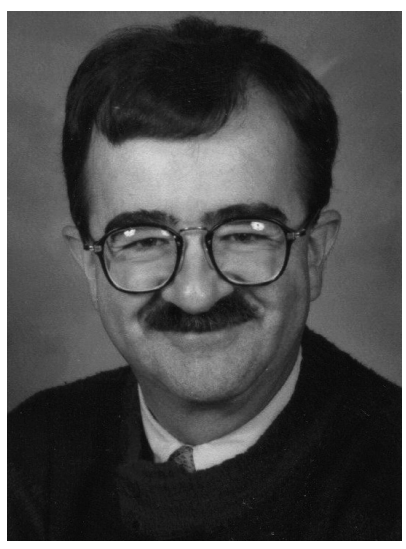
de banquets ou de retrouvailles dans son village. D'un naturel désarmant, doté d'une voix tonitruante et d'un sens de l'imitation achevé, que ce soit devant un prince de l'Église ou un employé d'usine, il savait avec ses mots de tous les jours et son humour faire revivre les événements et souligner les traits de caractère du plus humble au plus grand. Ceux qui l'ont connu au temps des Archives de folklore se souviendront de son fameux «Baptiste Béland ", l'homme-cheval qu'il avait même personnifié pour notre plus grand bonheur tout juste après sa soutenance de maîtrise.

Mais revenons à son parcours académique et professionnel. À l'Université Laval, il obtient une licence ès lettres en Civilisation canadienne et une maîtrise en Arts et traditions populaires sous la direction de Jean Du Berger. Son goût du théâtre peut-être et des personnages de légende l'amènent tout naturellement à s'intéresser à l'homme-cheval de la Beauce dont il fera le thème de son mémoire de fin de baccalauréat: "Jean-Baptiste Béland, homme-spectacle ${ }^{1} »$. Mais sa fascination pour l'inusité et la marginalité se manifestera aussi dans le choix de son sujet d'étude de maîtrise qui s'intitule « Les Revenants dans la Beauce québécoise ». Ses recherches seront d'ailleurs publiées chez Boréal Express en 1977 et rééditées en 1995 sous le titre Les

1. Paul Jacob, « Jean-Baptiste Béland, homme-spectacle », Nord, $\mathrm{n}^{\circ} 7$ « Contes et légendes », Sillery, Éditions de l'Hôte, automne 1977, p. 117-135. 
Revenants de la Beauce ${ }^{2}$. Les enquêtes qu'il mène lui font parcourir tous les petits chemins de la Beauce pour rencontrer des informateurs qui lui révèlent des faits et des anecdotes autour des revenants et, par ricochet, des rites de la mort. Cette incursion dans la pratique religieuse se cristallisera autour du culte populaire et du culte liturgique à Saint-Séverin de Beauce et à son typique - ou devrions-nous dire atypique - curé, l'abbé Arsenault ${ }^{3}$. C'est là aussi qu'il fera la connaissance de l'informatrice, conteuse et chanteuse hors pair qu'était Valéda Richard. Enfin il s'intéressera aux niches de croix de chemin dans la connaissance des dévotions populaires du Beauceron. L'ensemble de ses enquêtes et de ses recherches aura toujours pour épicentre la Beauce et les Beaucerons qu'il affectionnait particulièrement ${ }^{4}$.

Mais la véritable passion de Paul Jacob aura toujours été l'enseignement qu'il a pratiqué pendant 32 ans et plus particulièrement l'enseignement prodigué aux jeunes à Beauceville, Saint-Joseph et Saint-Martin dans la Beauce. Il les initie à la langue française, à la littérature et au conte, car son enseignement puisera toujours aux sources explorées du folklore et des traditions. Une anecdote à ce sujet. Paul s'impliquait tellement dans ses cours que, lancé dans le récit d'une légende où il mettait beaucoup d'enthousiasme et de grandiloquence, il a réussi à se casser le poignet en frappant sur son bureau. Passionné, il voudra transmettre cette ferveur à ses étudiants qu'il initiera d'ailleurs à la collecte d'informations dans leurs milieux respectifs.

Son parcours beauceron sera interrompu par deux séjours à l'Université Laurentienne (Sudbury) où il côtoiera et travaillera avec le père Germain Lemieux à la préparation de la série Les vieux m'ont conté. Malgré le bonheur de cette coopération, l'appel de la Beauce sera le plus fort et il reviendra y poursuivre sa carrière.

Paul Jacob était aussi mon beau-frère et cette relation particulière m'a permis de goûter à la beauté de son écriture ; le style, les mots et le papier même faisaient partie d'un tout. Jamais Paul n'écrivait une note qui ne soit une petite œuvre d'art. Les souvenirs d'enfance, les photos des êtres chers, les tables bien mises, les fleurs, les cadeaux donnés ou offerts auront été pour lui synonymes de bonheur tranquille et doux.

Jocelyne MiLot

Musée royal $22^{\mathrm{e}}$ régiment, Citadelle de Québec

2. Paul Jacob, Les Revenants de la Beauce, [préface de Robert Cliche], Montréal, Éditions du Boréal Express, 1977, 159 p. Ill. ; 2 édition, 1995, 159 p. Ill.

3. Paul Jacob et Antonio Arsenault, «La Mystique des Beaucerons » dans Jean Simard, en collaboration avec Jocelyne Milot et René Bouchard, Un patrimoine méprisé. La religion populaire des Québécois, Cité de LaSalle, Hurtubise HMH « Cahiers du Québec », 1979, p. 46-60.

4. On peut consulter ses collections déposées aux Archives de folklore et d'ethnologie de l'Université Laval (fonds Paul Jacob F611, et fonds Paul Jacob et Micheline Thibault F612, dont les données s'arrêtent à 1976) ; sa documentation restante sera prochainement versée au Musée Marius-Barbeau à Saint-Josephde-Beauce. 